\title{
The Potential Roles of Epigallocatechin-3-Gallate in the Treatment of Ovarian Cancer: Current State of Knowledge
}

This article was published in the following Dove Press journal: Drug Design, Development and Therapy

\section{Sabrina Bimonte $\mathbb{D}$ \\ Marco Cascella (D)}

Division of Anesthesia and Pain Medicine, Istituto Nazionale Tumori - IRCCS -

"Fondazione G. Pascale, Naples, Italy
Correspondence: Sabrina Bimonte Email s.bimonte@istitutotumori.na.it

\begin{abstract}
Ovarian cancer represents the principal leading cause of women dying in the world. The first standard of care involved surgical resection followed by chemotherapy with taxane and platinum, mainly connected with cytotoxic chemotherapies causing diverse severe side effects. Unfortunately, recurrence represents a significant problem, and finally, patients develop resistance to cytotoxic chemotherapy. Other alternative treatments had been developed so far to reduce side effects; however, the outcomes are yet not empowering. Current shreds of evidence showed that epigallocatechin-3-gallate (EGCG) possesses an anticancer effect on ovarian carcinoma, mainly through the inhibition of different genetic signaling pathways which are closely linked with tumorigenesis. This review recapitulates these findings and highlights the roles of EGCG for the chemoprevention and treatment of ovarian cancer.
\end{abstract}

Keywords: epigallocatechin-3-gallate, EGCG, ovarian cancer, antitumor properties, chemoprevention

\section{Introduction}

Epigallocatechin-3-gallate (EGCG), a dominant biologically active polyphenol of green tea, possesses antioxidant, antitumor and anti-inflammatory features. ${ }^{1-3}$ Current shreds of experimental findings showed that EGCG acts as an anti-cancer agent facing a different type of cancer cell lines, ${ }^{4-8}$ along with ovarian cancer cells. ${ }^{9}$ Of note, ovarian cancer is a specific type of gynecological tumor representing the principal cause of death worldwide and the highest mortality rate. ${ }^{10}$ Unfortunately, although significant results have been obtained for the clinical management of patients presenting this tumor, the underlying molecular mechanisms are not still elucidated. ${ }^{11}$ Interestingly as reported by Boussios et al, an important molecular mechanism potentially involved in the treatment of ovarian cancer is based on the synthetic lethal interaction between the inhibition of PARP and BRCA1/2 mutations. Authors underlined that additional tumorigenic pathways affected by PARP inhibition as monotherapy or in combination with other cytotoxic and biologic agents should be dissected in order to enhance the antitumor efficacy of PARP. ${ }^{12}$ To ameliorate the prognosis and the treatment of this type of cancer is extremely necessary to elaborate on new alternative therapies. Accumulated pieces of preclinical studies tried to depict the role of EGCG in the development of ovarian cancer and the related genetic pathways. Here, we revised the data published in the 
literature and highlighted the EGCG roles in the chemoprevention and in the development of ovarian cancer. Additionally, a new observation for translational perspectives into clinical practice has been proposed.

\section{EGCG Inhibited the Growth of Ovarian Cancer Cells: Preclinical Studies}

Several experimental studies demonstrated that EGCG exerts anticancer activities in several types of ovarian carcinoma cell lines through the modulation of diverse genetic signaling pathways (Table 1). Hu et al and Kim et al showed in two different studies, that EGCG suppressed the growth of ovarian cancer cells through the induction of the cell apoptosis and by stopping the cell cycle at the G1 phase. Moreover, the authors showed that EGCG was able to regulate the expression pattern of genes and proteins associated with cell-cycle as p21, Bax, Retinoblastoma, cyclin D1, Cyclin-dependent kinase 4 (CDK4), B-cell lymphoma-extra-large Bcl-X (L). ${ }^{13,14}$ Subsequently, Spinella et al demonstrated that EGCG arrested the growth of ovarian cancer cells (HEY and OVCA 433 cells) through a complex mechanism leading to the activation of cyclooxygenase (COX)-1and COX-2-dependent pathways which, in turn, are regulated by endothelin (ET) A receptor (ET (A) R)/ ET-1 endothelin-1 autocrine pathway. This pathway is normally overexpressed in ovarian cancer thus promoting its growth and neo-angiogenesis. Specifically, the authors showed that EGCG by inhibiting the expression of ET-1/ET (A) R, ET (A) R-mediated COX-1/2 mRNA, and the activity of COX-2 promoter, reduced the production of the prostaglandin E2 derived from COX-1/2 (PGE2). In this way, EGCG suppressed ovarian cancer cell growth. ${ }^{15}$ A fascinating study performed by Ravindranath et al highlighted an inhibitory role of the epicatechin (EC), EC 3-gallate (ECG) and EGCG on the growth of epithelial ovarian cancer cells (HH450, HH639) and prostate cancer cells (HH87, DU145) when used at different concentrations. ${ }^{16}$ Later on, Spinella et $\mathrm{al}^{17}$ confirmed that EGCG across the activation of caspase and the downregulating of Bcl-XL expression arrested the growth of ovarian cancer cells and thus promoted their apoptosis. At a molecular level, EGCG interfered with the activation of the p42/p44 ETAR-dependent pathway and with p38 mitogenactivated protein kinases (MAPKs) and phosphatidylinositol 3-kinase (AKT) pathways. Moreover, EGCG lowered the vascular endothelial growth factor (VEGF) production and decreased the activity of metalloproteinases (MMPs). Finally, EGCG (orally administered) suppressed the tumor growth in the HEY ovarian carcinoma mouse model. A different study underlined an anticancer role of EGCG in SKOV3 cells by suppressing the function of the heat-shock protein 90 (Hsp90). The authors demonstrated that EGCG, bound to Hsp90, arrested the recognition of the AhR response element (AhRE) and downregulated the expression of Ererb-b2 receptor tyrosine kinase 2 (ErbB2), v-raf-1 murine leukemia viral oncogene homolog 1(Raf-1), and phospho-AKT (p-AKT). ${ }^{18}$ In the same ovarian cancer cell lines, Rao et al showed that EGCG inhibited cell viability and proliferation thought the arrest of cell cycle arrest cells in S-phase (DNA synthesis) and G2-phase and the cells' accumulation in the apoptotic phase. ${ }^{19}$ Similarly, Yan et $\mathrm{al}^{20}$ showed that EGCG arrested the proliferation and enhanced the apoptosis of SKOV3 cells by downregulating aquaporin 5 (AQP5) expression which is strictly connected with NF- $\mathrm{B}$ pathway (downregulation of nuclear $\mathrm{p} 65$ and $\mathrm{I} \kappa \mathrm{B} \alpha$ ). Later on, Wang et al showed that EGCG (depending on the time and doses used) arrested the proliferation and the migration of OVCAR 3 cells by activating the p38-MAPK phosphorylation and by downregulated the MMP2 expression. ${ }^{21}$ Other studies demonstrated that the anticancer roles of EGCG in ovarian cancer cells should be enhanced by co-treatment with other natural compounds as thymoquinone (TQ) $)^{22}$ and other anti-inflammatory phytochemicals. $^{21}$ Interesting results have been obtained by integrative bioinformatics analysis and chemical fragment analysis performed by Xinqiang et al. ${ }^{23}$ By using this approach, the authors identified specific proteins by which EGCG can regulate the development of ovarian cancer, shedding a light on the underlying molecular mechanisms. Moreover, Wang et al demonstrated in vitro that EGCG inhibited PARP16, by suppressing the endoplasmic reticulum stress-induced phosphorylation of PERK and the transcription of UPR-related genes. This resulted in an increase of the cancer cells' apoptosis under endoplasmic reticulum stress conditions. $^{24}$

Overall, these reports indicate that EGCG alone or combined with other natural compounds should be considered a valuable therapeutic agent in ovarian cancer progression, although additional studies will be necessary. 
Table I A Summary of in vitro Studies on the Role of EGCG in Ovarian Cancer Cell Growth

\begin{tabular}{|c|c|c|c|}
\hline Cell Lines & Dose of EGCG & Molecular Targets & Reference \\
\hline $\begin{array}{l}\text { p53 negative, SKOV-3 cells; mutant } \\
\text { type p53, OVCAR- } 3 \text { cells; and wild } \\
\text { type p53, PA-I cells }\end{array}$ & 6.25 to $100 \mu \mathrm{M}$ & $\begin{array}{l}\mathrm{P} 2 \mathrm{I} \uparrow, \mathrm{Bax} \uparrow, \text { Retinoblastoma, } \\
\text { cyclin DI } \uparrow, \mathrm{BCL}-\mathrm{X}_{\mathrm{L} \downarrow}, \\
\mathrm{PCNA} \downarrow\end{array}$ & 13,14 \\
\hline HEY, OVCA 433 & $5,10 \mu \mathrm{M}$ & $\begin{array}{l}\text { ET-I/ET (A) R } \downarrow, E T(A) \\
\text { R-mediated COX-I/2 } \\
\text { mRNA } \downarrow, \text { COX-2 } \downarrow, \text { PGE } 2 \downarrow\end{array}$ & 15 \\
\hline $\begin{array}{l}\text { HH870, DUI } 45 \text { prostate cancer } \\
\text { cells, } \mathrm{HH} 450, \mathrm{HH} 639 \text { ovarian cancer } \\
\text { cells }\end{array}$ & $25,50,75$ or $100 \mu \mathrm{M}$ & $\begin{array}{l}\text { Cancer cell growth } \\
\text { suppressor }\end{array}$ & 16 \\
\hline HEY, OVCA 433 & $10 \mu \mathrm{mol} / \mathrm{L}, 20,40 \mu \mathrm{mol} / \mathrm{L}$ & $\begin{array}{l}E T-I / E T_{A} R, \downarrow p 38, p 42 / p 44 \downarrow \\
\text { MAPKs } \downarrow, A K T \downarrow\end{array}$ & 17 \\
\hline SKOV3 & $2-200 \mu \mathrm{M}$ & $\begin{array}{l}\text { ErbB } 2 \downarrow, \text { Raf- I } \downarrow \text {, phospho- } \\
\text { AKT } \downarrow, \text { Hsp90 } \downarrow\end{array}$ & 18 \\
\hline SKOV3 & $0-80 \mu \mathrm{g} / \mathrm{mL}$ & $\begin{array}{l}\text { Cell cycle arrest in cells in } \\
\text { S-phase (DNA synthesis) } \\
\text { and G2-phase. }\end{array}$ & 19 \\
\hline SKOV3 & $\begin{array}{l}\text { EGCG }(20,40,60,80 \text { or } 100 \mathrm{lg} / \mathrm{mL}) \text { or PDTC }(0.1, \mathrm{I} \text { or } 10 \\
\mathrm{mM}) \text { for } 24 \mathrm{~h} \text { treated for different time periods with } 40 \mathrm{lg} / \\
\mathrm{mL} \text { EGCG for } 6,12,24,48 \text { or } 72 \mathrm{~h} \text { or treated with I } \mathrm{mmol} \\
\text { PDTC for } 12,24 \text { or } 48 \mathrm{~h} \text {. }\end{array}$ & 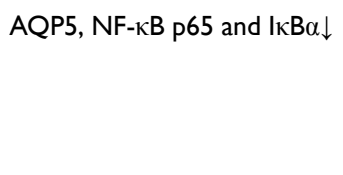 & 20 \\
\hline OVCAR-3 & $0-100 \mu \mathrm{M}$ & MMP- $2 \downarrow$ P38-MAPK $\uparrow$ & 21 \\
\hline
\end{tabular}

Notes: $\uparrow$ upregulated, $\downarrow$ downregulated.

Abbreviations: EGCG, epigallocatechin-3-gallate; P2I, cyclin-dependent kinase inhibitor I; Bax, BCL2 associated X, apoptosis regulator; BCL-XL, B-cell lymphoma-extralarge; PCNA, proliferating cell nuclear antigen; ET-I/ET (A)R, endothelin I (ET-I) and its receptor endothelin receptor A (ETAR); COX-I/2, cyclooxygenase-I/2; mRNA, micro-RNA; PGE2, prostaglandin E2; MAPK, mitogen-activated protein kinase; AKT, protein kinase B; ErbB2, ErbB2 receptor tyrosine kinase 2; Raf-I, v-raf-I murine leukemia viral oncogene homolog I; Hsp90, heat-shock protein 90; AQP5, aquaporin-5; NF-kB, nuclear factor kappa-light-chain-enhancer of activated B cells; PDTC, pyrrolidine dithiocarbamate; $1 \kappa \mathrm{B} \alpha$, nuclear factor of kappa light polypeptide gene enhancer in B-cells inhibitor, alpha; MMP-2, matrix metalloproteinase-2.

\section{Chemopreventive Roles of EGCG in Ovarian Cancer}

Different preclinical studies highlighted also the chemopreventive properties of EGCG against ovarian cancer (Table 2). Chan et al ${ }^{25}$ demonstrated that EGCG inhibited the growth of diverse ovarian cancer cell lines including those resistant to cisplatin. Specifically, EGCG enhanced the oxidative stress and the susceptibility of ovarian cancer cells to cisplatin. Similarly, Yunos et al demonstrated synergistic effects between the sequenced combinations of cisplatin (Cis) with curcumin (Cur) and epigallocatechin-3-gallate (EGCG) in the several human ovarian cancer cells. Specifically, the authors demonstrated that lower concentrations and the shorter time gap between the additions of sequenced combinations of $\mathrm{Cis}$ with Cur and EGCG in the human ovarian cancer cell lines resulted in a higher cytotoxic effect. ${ }^{26}$ Similarly, results were obtained by treating the A2780 and A2780cisR cells with oxaliplatin (Oxa) with other phytochemicals including EGCG. Specifically, a synergistic effect was observed by administrating Oxa $4 \mathrm{~h}$ before the phytochemicals in A2780 and A2780cisR cells, thus bypassing ovarian cancer resistance to the drug. ${ }^{27}$ Again, Mazumder et al showed that the sequenced combinations of platinum drugs and tumor-active palladium compounds transpalladiums (TH5, TH6, and TH7) treated with EGCG bypassed cancer resistance to drug. ${ }^{28}$ Similarly, Chen and co-authors showed that EGCG combined with sulforaphane (SFN) induced the apoptosis in paclitaxel-sensitive (SKOV3-ip1) and-resistant (SKOV3TR-ip2) ovarian cancer cell lines by down-regulation of human Telomerase reverse transcriptase (hTERT, a protein strictly involved in the survival of cancer cells) and Bcl-2. Taken together these findings suggest these compounds should be used to bypass the paclitaxel resistance in the treatment of ovarian cancer. ${ }^{29}$ Later on, the same authors demonstrated that the combination of EGCG with SFN was effective to 
Table 2 Chemopreventive Role of EGCG in Ovarian Cancer

\begin{tabular}{|c|c|c|c|}
\hline Cell Lines & Drugs and Doses & Effects & Reference \\
\hline $\begin{array}{l}\text { SKOV3, CAOV3, OVCAR3, } \\
\text { OVCARI0, A2780, CP70, C } 30 \text {, } \\
\text { C200 }\end{array}$ & $\begin{array}{l}\text { EGCG }(0-20 \mathrm{mM}) \text {. } \\
\text { Cis }(1-4 \mu g / \mathrm{mL})\end{array}$ & $\begin{array}{l}\text { EGCG may accentuate oxidative stress to } \\
\text { inhibit growth of ovarian cancer cells and } \\
\text { sensitize them to cisplatin }\end{array}$ & 25 \\
\hline $\begin{array}{l}\text { A2780, A2780cisR, } \\
\text { A2780ZD0473R }\end{array}$ & $\begin{array}{l}\text { EGCG (at different doses) } \\
\text { Cis (at different doses) } \\
\text { Cu (at different doses) } \\
\text { at } 0 / 0 \mathrm{~h}, 4 / 0 \mathrm{~h}, 0 / 4 \mathrm{~h}, 24 / 0 \mathrm{~h} \text { and } 0 / 24 \mathrm{~h} .\end{array}$ & $\begin{array}{l}\text { Lower concentrations and shorter time gap } \\
\text { between the additions of sequenced } \\
\text { combinations of Cis with Cur and EGCG in the } \\
\text { human ovarian cancer cell lines produced } \\
\text { a higher cytotoxic effect. }\end{array}$ & 26 \\
\hline A2780, A2780cisR & $\begin{array}{l}\text { Oxa }(0.0005 \text { to } 100 \mu \mathrm{M}) \\
\text { Andro, EGCG, Chl, Col, Cur, Tax (at different } \\
\text { doses) }\end{array}$ & $\begin{array}{l}\text { Synergism between Oxa and phytochemical } \\
\text { was effective in cisplatin resistant as well as } \\
\text { non-resistant ovarian cancer cell lines }\end{array}$ & 27 \\
\hline $\mathrm{A} 2780, \mathrm{~A} 2780$ (cisR) & $\begin{array}{l}\text { EGCG }(1.33-21.21 .98 \mu \mathrm{M}) \\
\text { Cis }(0.08-15.87 \mu \mathrm{M}) \\
\text { TH5 }(2.73-56.67 \mu \mathrm{M}) \text { TH6 }(0.87-14.30 \mu \mathrm{M}) \\
\text { TH7 }(2.39-43.37 \mu \mathrm{M}) \text { for } 0 / 0 \mathrm{~h}, 0 / 4 \mathrm{~h} \text { and } 4 / 0 \mathrm{~h}\end{array}$ & $\begin{array}{l}\text { EGCG combined with cis and TH5, TH6 and } \\
\text { TH7 acts synergistically in A2780 A2780(cisR) } \\
\text { cells }\end{array}$ & 28 \\
\hline SKOV3-ipI, SKOV3TR-ip2 & $\begin{array}{l}\text { EGCG }(5,10,20,30 \mu \mathrm{mol} / \mathrm{L}) \text { or SFN }(7.5,10 \text {, } \\
15 \mu \mathrm{mol} / \mathrm{L}) \text { or combination of EGCG and SFN } \\
(5+7.5,10+7.5,20+7.5,30+7.5 ; 10+10,20+10 \text {, } \\
30+10 ; 10+10,20+10,30+10 \mu \mathrm{mol} / \mathrm{L}) \text { for } 24 \text {, } \\
48 \text { and } 72 \mathrm{~h} \text {. }\end{array}$ & $\begin{array}{l}\text { EGCG combined with SFN arrested ovarian } \\
\text { cancer cells growth by downregulated the } \\
\text { expression of decreasing Bcl-2 and hTERT. }\end{array}$ & 29 \\
\hline $\mathrm{A} 2780, \mathrm{~A} 2780 / \mathrm{CP} 20$ & $\begin{array}{l}\text { EGCG }(2.5,5,10,20 \text {, and } 40 \mu \mathrm{M}), \operatorname{SFN}(2.5,5 \text {, } \\
10,15 \text {, and } 20 \mu \mathrm{M})\end{array}$ & $\begin{array}{l}\text { EGCG combined with SFN upregulated } \mathrm{p} 2 \mathrm{I} \\
\text { expression induced by cisplatin in ovarian } \\
\text { cancer cells and arrested the cells in the G2/M } \\
\text { phase of cell cycle. }\end{array}$ & 30 \\
\hline $\begin{array}{l}\text { SKOV3, OVCAR3 (ovarian } \\
\text { cancer cells) HEK-293T } \\
\text { (human embryonic kidney } \\
\text { cells) } \\
\text { OVCAR3 ovarian xenograft } \\
\text { model ( } 5 \times 10^{6} \text { subcutaneously } \\
\text { injected into the dorsum of the } \\
\text { mice). }\end{array}$ & $\begin{array}{l}\text { EGCG }(0-20 \mu \mathrm{M}) \text { cDDP }(0-40 \mu \mathrm{M}) \text { in ovarian } \\
\text { cancer cells. } \\
\text { Xenograft mouse model of ovarian cancer: } \\
\text { Control (normal saline, } 0.1 \mathrm{~mL} / 10 \mathrm{~g}) \text {, EGCG } \\
(20 \mathrm{mg} / \mathrm{kg}), \mathrm{cDDP}(5 \mathrm{mg} / \mathrm{kg}), \text { EGCG }(20 \mathrm{mg} / \mathrm{kg}) \\
\text { and cDDP }(5 \mathrm{mg} / \mathrm{kg}) \text { for } 4 \text { weeks. }\end{array}$ & $\begin{array}{l}\text { EGCG combined with cDDP increased the } \\
\text { accumulation of cDDP and DNA-Pt adducts } \\
\text { and enhanced the sensitivity of ovarian cancer } \\
\text { SKOV3 and OVCAR3 cells to the } \\
\text { chemotherapeutic agent. In a mouse model of } \\
\text { OVCAR3 ovarian cancer, the combination of } \\
\text { the lower concentration of cDDP and EGCG } \\
\text { strongly repressed the tumor growth nd } \\
\text { exhibited protective effect on the } \\
\text { nephrotoxicity induced by cisplatin. }\end{array}$ & 31 \\
\hline $\begin{array}{l}\text { Ovarian tissue of three patients } \\
\text { without non-gynecological } \\
\text { diseases }\end{array}$ & $\begin{array}{l}\text { EGCG }(10 \mu g / m L) \\
\text { DOX }(I \mu g / m L) \text { for } 24 \text { and } 48 \mathrm{~h} .\end{array}$ & $\begin{array}{l}\text { EGCG inhibits dox-induced inflammation on } \\
\text { human ovarian tissue. EGCG altered the } \\
\text { expression of TNF- } \alpha \text {, COX-2, IL- } 6 \text { IL-8, MMP2 } \\
\text { and MMP9 }\end{array}$ & 32 \\
\hline
\end{tabular}

Abbreviations: EGCG, epigallo-catechin-3-gallate; Cis, cisplatin; Cur, curcumin; Oxa, oxaliplatin; Andro, andrographolide; Chl, chlorophyllin; Col, colchicines; Tax, paclitaxel; TH5, trans-palladium-5; TH6, trans-palladiums-6; TH7, trans-palladiums-7; SFN, sulforaphane; cDDP, cisplatin; DOX, doxorubicin; TNF- $\alpha$, tumor necrosis factor- $\alpha$; COX-2, cyclooxigenase-2; IL-6, inflammatory interleukin-6; IL-8, and interleukin-8 (IL-8); MMP-2, metalloproteinase-2; MMP-9, metalloproteinase-9.

overcome the chemoresistance of A2780 and A2780/CP20 cells to cisplatin. Specifically, the authors showed that EGCG, by upregulating the expression of $\mathrm{p} 21$, enhanced the $\mathrm{G} 2 / \mathrm{M}$ phase arrest induced by SFN thus inhibiting the proliferation and inducing the apoptosis of both lines of ovarian carcinoma cells. ${ }^{30}$ Interesting findings were obtained by Wang et $\mathrm{al}^{31}{ }^{31}$ which highlighted roles of EGCG on copper transporter 1 (CTR1) and the uptake and efflux of cisplatin (CDDP) in ovary cancer cells and xenograft mice. In vitro studies on OVCAR3, SKOV3 
cells showed that EGCG increased the sensitivity of these cells to cDDP, presumably associated with an upregulation of CTR1 and an increased accumulation of cDDP. In a mouse model of OVCAR3 ovarian cancer, the combination of the lower concentration of cDDP and EGCG inhibited the growth of tumors and showed a protective effect on the nephrotoxicity induced by cisplatin. Recently, it has been highlighted a protective role of EGCG from the inflammation caused by DOX in the human ovarian tissues collected from patients without gynecological diseases. ${ }^{32}$ Finally, Boussios et al reported interesting data about Hsp90 and ovarian cancer. It is of note that Hsp90 acting by folding client proteins and by preventing them from degradation by the ubiquitin-proteasome system. Authors proved an in vivo evidence for synergism between the PARP inhibitor olaparib and HSP90-inhibitor AT13387, in PARP inhibitor-resistant ovarian cancer. ${ }^{33}$ Altogether, these reports strongly suggest that EGCG should be used as a chemopreventive substance in ovarian cancer treatment.

\section{Conclusions and Clinical Perspectives}

Accumulated shreds of evidence highlighted anticancer and chemopreventive roles of EGCG in ovarian cancer across the regulation of several molecular pathways. These data strongly support the adoption of EGCG into the clinical management of patients suffering from ovarian cancer. Unfortunately, no clinical trial has been performed with EGCG on patients with ovarian cancer, more studies will be necessary not only to explore the molecular mechanism influenced by EGCG in ovarian cancer but also to define the exact EGCG's dose to use in clinical trials on patients with ovarian tumors.

\section{Acknowledgments}

We are grateful to Dr. Alessandra Trocino and Mrs. Cristina Romano from the National Cancer Institute of Naples for providing excellent bibliographic service and assistance.

\section{Author Contributions}

The present review was mainly written by SB and MC. All authors contributed toward data analysis, drafting and critically revising the paper, gave final approval of the version to be published, and agree to be accountable for all aspects of the work.

\section{Disclosure}

The authors report no conflicts of interest in this work.

\section{References}

1. Nakachi K, Matsuyama S, Miyake S, et al. Preventive effects of drinking green tea on cancer and cardiovascular disease: epidemiological evidence for multiple targeting prevention. BioFactors. 2000;13(1-4):49-54. doi:10.1002/biof.5520130109

2. Kurahashi N, Sasazuki S, Iwasaki M, et al. Study group green tea consumption and prostate cancer risk in Japanese men: a prospective study. Am J Epidemiol. 2007;167(1):71-77. doi:10.1093/aje/kwm249

3. Yang CS, Landau JM, Huang MT, et al. Inhibition of carcinogenesis by dietary polyphenolic compounds. Annu Rev Nutr. 2001;21 (1):381-406. doi:10.1146/annurev.nutr.21.1.381

4. Bimonte S, Cascella M, Barbieri A, et al. Current shreds of evidence on the anticancer role of EGCG in triple negative breast cancer: an update of the current state of knowledge. Infect Agent Cancer. 2020;15(1):2. doi:10.1186/s13027-020-0270-5

5. Bimonte S, Cascella M, Barbieri A, et al. Shining a light on the effects of the combination of (-)-Epigallocatechin-3-gallate and tapentadol on the growth of human triple-negative breast cancer cells. In Vivo (Brooklyn). 2019;33(5):1463-1468. doi:10.21873/ invivo. 11625

6. Bimonte S, Albino V, Piccirillo M, et al. Epigallocatechin-3-gallate in the prevention and treatment of hepatocellular carcinoma: experimental findings and translational perspectives. Drug Des Devel Ther. 2019;13:611-621. doi:10.2147/DDDT.S180079

7. Bimonte S, Cascella M, Leongito $\mathrm{M}$, et al. An overview of pre-clinical studies on the effects of (-)-epigallocatechin-3-gallate, a catechin found in green tea, in treatment of pancreatic cancer. Recenti Prog Med. 2017;108(6):282-287. doi:10.1701/2715.27715

8. Bimonte S, Cascella M, Leongito $\mathrm{M}$, et al. An overview of pre-clinical studies on the effects of (-)-epigallocatechin-3-gallate, a catechin found in green tea, in treatment of pancreatic cancer. Recenti Prog Med. 2017;108(6):282-287. doi:10.1701/2715.27715

9. Niedzwiecki A, Roomi MW, Kalinovsky T, Rath M. Anticancer efficacy of polyphenols and their combinations. Nutrients. 2016;8 (9):552. doi:10.3390/nu8090552

10. Bray F, Ferlay J, Soerjomataram I, Siegel RL, Torre LA, Jemal A. Global cancer statistics 2018: GLOBOCAN estimates of incidence and mortality worldwide for 36 cancers in 185 countries. CA Cancer J Clin. 2018;68(6):394-424. doi:10.3322/caac.21492

11. Lengyel E. Ovarian cancer development and metastasis. Am J Pathol. 2010;177(3):1053-1064. doi:10.2353/ajpath.2010.100105

12. Boussios S, Karihtala P, Moschetta M, et al. Combined strategies With poly (ADP-Ribose) polymerase (PARP) inhibitors for the treatment of ovarian cancer: a literature review. Diagnostics (Basel, Switzerland). 2019;9(3):87. doi:10.3390/diagnostics9030087

13. Hu SW, Bae SM, Kim YW, et al. Anticancer effects of (-)epigallocatechin-3-gallate on ovarian carcinoma cell lines. Gynecol Oncol. 2004;94(3):760-768.

14. Kim YW, Bae SM, Lee JM, et al. Activity of green tea polyphenol epigallocatechin-3-gallate against ovarian carcinoma cell lines. Cancer Res Treat. 2004;36(5):315-323. doi:10.4143/ crt.2004.36.5.315

15. Spinella F, Rosanò L, Decandia S, et al. Antitumor effect of green tea polyphenol epigallocatechin-3-gallate in ovarian carcinoma cells: evidence for the endothelin-1 as a potential target. Exp Biol Med (Maywood). 2006;231(6):1123-1127.

16. Ravindranath MH, Saravanan TS, Monteclaro CC, et al. Epicatechins purified from green tea (camellia sinensis) differentially suppress growth of gender-dependent human cancer cell lines. Evid Based Complement Alternat Med. 2006;3(2):237-247. doi:10.1093/ecam/ nel003 
17. Spinella F, Rosanò L, Di Castro V, et al. Green tea polyphenol epigallocatechin-3-gallate inhibits the endothelin axis and downstream signaling pathways in ovarian carcinoma. Mol Cancer Ther. 2006;5(6):1483-1492. doi:10.1158/1535-7163.MCT-06-0053

18. Yin Z, Henry EC, Gasiewicz TA. (-)-Epigallocatechin-3-gallate is a novel Hsp90 inhibitor†. Biochemistry. 2009;48(2):336-345. doi:10.1021/bi801637q

19. Rao SD, Pagidas K. Epigallocatechin-3-gallate, a natural polyphenol, inhibits cell proliferation and induces apoptosis in human ovarian cancer cells. Anticancer Res. 2010;30(7):2519-2523.

20. Yan C, Yang J, Shen L, et al. Inhibitory effect of Epigallocatechin gallate on ovarian cancer cell proliferation associated with aquaporin 5 expression. Arch Gynecol Obstet. 2012;285(2):459-467. doi:10.1007/s00404-011-1942-6

21. Wang F, Chang Z, Fan Q, et al. Epigallocatechin-3-gallate inhibits the proliferation and migration of human ovarian carcinoma cells by modulating p38 kinase and matrix metalloproteinase-2. Mol Med Rep. 2014;9(3):1085-1089. doi:10.3892/mmr.2014.1909

22. Harpole JL, Tucci M, Benghuzzi H. Pathophysiological effects of thymoquinone and Epigallocatechin-3-gallate on SK-OV-3 ovarian cancer like cell line. Biomed Sci Instrum. 2015;51:31-39.

23. Xinqiang $\mathrm{S}, \mathrm{Mu} \mathrm{Z}$, Lei $\mathrm{C}$, Mun LY. Bioinformatics analysis on molecular mechanism of green tea compound Epigallocatechin-3-gallate against ovarian cancer. Clin Transl Sci. 2017;10(4):302-307. doi:10.1111/cts. 12470

24. Wang J, Zhu C, Song D, et al. Epigallocatechin-3-gallate enhances ER stress-induced cancer cell apoptosis by directly targeting PARP16 activity. Cell Death Discov. 2017;3(1):17034. doi:10.1038/ cddiscovery.2017.34

25. Chan MM, Soprano K, Weinstein K, et al. Epigallocatechin-3-gallate delivers hydrogen peroxide to induce death of ovarian cancer cells and enhances their cisplatin susceptibility. J Cell Physiol. 2006;207 (2):389-396. doi:10.1002/jcp.20569
26. Yunos NM, Beale P, Yu JQ, et al. Synergism from sequenced combinations of curcumin and epigallocatechin-3-gallate with cisplatin in the killing of human ovarian cancer cells. Anticancer Res. 2011;31 (4):1131-1140.

27. Yunos NM, Beale P, Yu JQ, et al. Synergism from the combination of oxaliplatin with selected phytochemicals in human ovarian cancer cell lines. Anticancer Res. 2011;31(12):4283-4289.

28. Mazumder ME, Beale P, Chan C, et al. Epigallocatechin gallate acts synergistically in combination with cisplatin and designed trans-palladiums in ovarian cancer cells. Anticancer Res. 2012;32 (11):4851-4860.

29. Chen H, Landen CN, Li Y, et al. Epigallocatechin gallate and sulforaphane combination treatment induce apoptosis in paclitaxel-resistant ovarian cancer cells through hTERT and Bcl-2 down-regulation. Exp Cell Res. 2013;319(5):697-706. doi:10.1016/j.yexcr.2012.12.026

30. Chen H, Landen CN, Li Y, et al. Enhancement of cisplatin-mediated apoptosis in ovarian cancer cells through potentiating G2/M arrest and p21 upregulation by combinatorial epigallocatechin gallate and sulforaphane. J Oncol. 2013;2013:872957. doi:10.1155/2013/872957

31. Wang X, Jiang P, Wang P, et al. EGCG enhances cisplatin sensitivity by regulating expression of the copper and cisplatin influx transporter CTR1 in ovary cancer. PLoS One. 2015;10(4):e0125402. doi:10.1371/journal.pone.0125402

32. Fabbri R, Macciocca M, Vicenti R, et al. Epigallocatechin-3-gallate inhibits doxorubicin-induced inflammation on human ovarian tissue. Biosci Rep. 2019;39(5):BSR20181424. doi:10.1042/BSR20181424

33. Boussios S, Karathanasi A, Cooke D, et al. PARP inhibitors in ovarian cancer: the route to "Ithaca". Diagnostics (Basel). 2019;9 (2):55. doi:10.3390/diagnostics9020055

\section{Publish your work in this journal}

Drug Design, Development and Therapy is an international, peerreviewed open-access journal that spans the spectrum of drug design and development through to clinical applications. Clinical outcomes, patient safety, and programs for the development and effective, safe, and sustained use of medicines are a feature of the journal, which has also been accepted for indexing on PubMed Central. The manuscript management system is completely online and includes a very quick and fair peer-review system, which is all easy to use. Visit http://www. dovepress.com/testimonials.php to read real quotes from published authors. 